\title{
LINGUAGEM, SOCIEDADE E PODER: COLETÂNEA DE ARTIGOS
}

\author{
Mércia Regina Santana FLANNERY*
}

MOONEY,A.; PECCEI J. S.; LABELLE, S.; HENRIKESEN, B. E.; EPPLER, E.; IRWIN, A.; PICHLER, P.; SODEN, S. (Org.). The language, society and power reader. London: Routledge, 2011. 374p.

A coletânea de textos em The language, society and power reader abrange um variado número de artigos originais assinados por importantes e influentes estudiosos da linguística contemporânea, além de incluir trabalhos mais recentes de outros pesquisadores. Trata-se de um livro indispensável para estudantes da disciplina, interessados em acompanhar o rápido passo com que a linguística moderna tem se desenvolvido e observar aplicações da disciplina em diferentes áreas do conhecimento, refletindo a influência da linguagem em esferas distintas da experiência humana.

O livro destina-se primariamente àqueles que estão iniciando o estudo na área de linguística, mas constitui referência importante para quaisquer estudiosos da ciência da linguagem. É um material que pode facilitar a organização de cursos na área de Sociolinguística e Linguística Aplicada. A estruturação do livro em dez seções reflete a abrangência de seus textos componentes: cada seção é iniciada com um comentário sobre os artigos, no qual os autores apontam para termos importantes e noções fundamentais a serem observados nos capítulos sequenciais. Há também, nessa seção introdutória, sugestões adicionais de leitura sobre o tema e de filmes ou documentários que ilustram os pontos expressos nos artigos.

Na primeira seção, intitulada "Language and Power", há artigos de Deborah Cameron e Norman Fairclough. O primeiro, "Preface to verbal hygiene", é parte do importante trabalho de Cameron ${ }^{1}$ sobre a noção de higiene verbal, no qual a autora discute opiniões sobre usos linguísticos por "leigos" e linguistas. Ao discutir as diferenças no modo como esses dois grupos percebem a linguagem, a

\footnotetext{
* University of Pennsylvania. Romance Languages Department. 521 Williams Hall, 255 S 36th Street, Philadelphia, PA - EUA. 19104 - merciaf@sas.upenn.edu.

1 Cf. CAMERON, 1995.
} 
autora comenta que "[t]he overriding concern with value is the most significant characteristic that separates lay discourse on language from the expert discourse of linguists." (MOONEY et al., 2011, p.13). Cameron argumenta em favor de um engajamento por parte daqueles que se importam com os usos linguísticos, sejam estudiosos da linguagem ou observadores preocupados com os rumos que o uso de uma língua assumem com o passar do tempo. Como a autora mostra, grande parte das crenças sobre os usos linguísticos por não especialistas baseia-se em noções de certo e errado e são, via de regra, resultantes de preconceito e ignorância. Por isso, Cameron propõe que, antes de se aceitarem ideias sobre a linguagem e seus usos como "profound and insdispensable truths", deve-se dedicar à verificação da lógica por trás destas.

O artigo de Fairclough,2 "Global capitalism and critical awareness of language", propõe um entendimento crítico da linguagem como ferramenta fundamental de uma educação linguística. Para o autor, o entendimento de discursos largamente aceitos em uma determinada comunidade pode ser vital para a compreensão da realidade e para se exercer efetivamente a cidadania. O autor ilustra a importância dessa compreensão ao comentar sobre o discurso de "flexible accumulation", de acordo com o qual, nas sociedades modernas, as mudanças no modo de produção e daquilo que se produz resultam em uma mudança nas formas de trabalho e na redução de determinadas posições. De acordo com o autor, esse discurso ideologicamente carregado e sua aceitação reduzem a força reivindicativa dos trabalhadores.

A metáfora da flexibilidade, de acordo com Fairclough, penetra várias esferas da vida diária, incluindo a linguagem política e a mensagem dos chamados "gurus profissionais", que escrevem livros de conselho. Esse exemplo ilustra de que forma novas realidades discursivas são influenciadas ou modificadas, à medida que novos conhecimentos e práticas econômicas são postos em prática. A preocupação do autor, porém, não é em termos do valor absoluto de verdade desses discursos, mas em termos de "ganhos epistêmicos", ou de como e se a compreensão da existência dessa forma de mediar a realidade pode melhorar a forma como os indivíduos administram suas vidas. Isso leva ao próximo ponto de importância na discussão de Fairclough, o fato de que se vive, hoje, em sociedades cada vez mais textualmente mediadas e nas quais há mais e mais uma influência direta dos modos de percepção e representação da realidade nos modos de viver. Para Fairclough, "[a]s everyday lives become more pervasively textually mediated, people's lives are increasingly shaped by representations which are produced elsewhere." (MOONEY et al., 2011, p.21). A fluidez com que os discursos se contaminam e se espalham e o impacto de noções discursivas sobre as diferenças que marcam as sociedades modernas são também dignos de

2 Cf. FAIRCLOUGH, 1999. 
atenção em uma educação linguística que vise a formar indivíduos capazes de refletir sobre o perigo de se absorverem certos modelos, particularmente os que motivam o preconceito e a discriminação. Dessa forma, o artigo de Fairclough contribui à coletânea com a perspectiva de que um entendimento crítico das formas como o discurso pode: 1) mediar a realidade, 2) influenciar a forma como se entende o mundo e 3) salientar como, possivelmente, ações e modos de viver devem ser parte da contribuição de uma educação que vise a formar indivíduos para a vida.

Na segunda seção da coletânea - "Language and thought" - há dois artigos importantes para os estudos linguísticos contemporâneos. No primeiro, "The great eskimo vocabulary hoax", Geoffrey Pullum ${ }^{3}$ aborda "a falácia do vocabulário esquimó", traçando o início da abrangente, mas, de acordo com o autor, falsa noção de que, em esquimó, há uma multiplicidade de expressões para designar o referente "neve". De acordo com Pullum, "the myth of the multiple words for snow is based on almost nothing at all" (MOONEY et al., 2011, p.34). O autor traça o início do mal-entendido a um comentário de Franz Boas (1911) sobre como o inglês emprega variantes de uma mesma raiz (morfologia derivacional) para expressar diferentes noções, ao passo que ideias comparáveis em esquimó são expressas com o emprego de diferentes raízes. Em seguida, Whorf comenta o texto de Boas (1911), desenvolvendo a mesma ideia, mas extraindo-a do contexto original e, assim, atribuindo um sentido significativamente distinto do trabalho do antropólogo alemão. Pullum descreve posteriores apropriações e desenvolvimentos da noção de que há um número infinito de expressões para designar o referente "neve", concluindo com o seguinte comentário: "The tragedy is not that so many people got the facts wildly wrong; it is that in the mentally lazy and anti-intellectual world we live in today, hardly anyone cares enough to think about trying to determine what the facts are." (MOONEY et al., 2011, p.38). Para o autor, então, o artigo não é necessariamente uma tentativa de provar que estão errados os que repetem a bem difundida informação sobre o vocabulário esquimó, mas é uma chamada à atenção para que se busquem os fatos e a origem das informações.

A mesma seção inclui também um capítulo de Benjamin Whorf,, "The relation of habitual thought and behavior to language". Começando com uma citação de Sapir, de quem Whorf havia sido estudante, o capítulo traça a conexão entre linguagem e atividades culturais e pessoais. Whorf, que se formou em química e trabalhou como inspetor de uma companhia de seguros contra incêndio, extrai exemplos desta sua ocupação para ilustrar a relação entre linguagem e o exercício de atividades no dia a dia. O autor mostra, por exemplo, como o fato

\footnotetext{
3 Cf. PULLUM, 1991.

4 CF. WHORF, 1956.
} 
de indivíduos compreenderem a noção de "vazio" motivava alguns a lançarem uma ponta de cigarro em conteúdos nos quais elementos flamáveis haviam sido depositados anteriormente. Nesse caso, a consequência da ação das pessoas - um incêndio - requeria que se entendesse de que forma a compreensão do sentido de "vazio" havia motivado uma atitude perigosa. Whorf supre mais dois exemplos sobre como "as pessoas agem de forma a refletir o modo de se falar a respeito de determinadas situações"5: o autor contrasta a percepção da realidade tal como expressa através da língua Hopi e do que classifica como "Standard Average European"6. (MOONEY et al., 2011, p.47). De acordo com os exemplos dados, a realidade percebida e transmitida através da linguagem influencia a forma como agem diferentes indivíduos, organizados em grupos socioculturais distintos. A conclusão de Whorf - pode-se apontar uma conexão entre normas culturais e modelos linguísticos, mas não uma correlação - é ainda um dos princípios mais importantes nas atuais considerações e estudos na Sociolinguística moderna.

Na terceira seção, "Language and politics", três artigos discutem aplicações do estudo linguístico no âmbito do discurso político em países de três continentes: Estados Unidos, Tunísia, Holanda, Inglaterra e Suécia. O primeiro artigo, de Geoffrey Nunberg, "Media: label whores", comenta a noção de que se costuma atribuir a etiqueta "conservador" no caso dos comentaristas e jornalistas que adotam, claramente, posições à direita no eixo político americano. Entretanto, como o autor comenta, os chamados profissionais de jornalismo "liberais" são a tendência e, assim, prescindem de títulos. A curta discussão de Nunberg aponta para o fato de as tentativas de se atribuírem rótulos funcionarem mesmo para assegurar "que o escritor e a publicação estejam confortavelmente no centro" (MOONEY et al., 2011, p.71).

O artigo de Naïma Boussara-Omar7- "Learning the 'linguistic habitus' of a politician: a presidential authoritative voice in the making" - é uma análise de duas versões do discurso de posse do então presidente tunisiano Ben Ali. A primeira versão do discurso, anterior às correções, é analisada com vistas a se encontrarem as marcas que indicam uma voz incompatível com a posição de presidente e a busca de um papel de maior autoridade. Para Boussara-Omar, o processo de correções à primeira versão do discurso de Ben Ali revela uma nova autoridade discursiva e presidencial em desenvolvimento (MOONEY et al., 2011, p.74). A análise dessas duas versões auxilia na compreensão de como se lança mão de "capital linguístico" para a construção de posições de autoridade. Deve-se essa possibilidade ao potencial indexicalizador do signo linguístico e ao contexto de uso dos atores sociais.

\footnotetext{
5 No original: "as people act about situations in ways which are like the ways they talk about them".

6 Todas as traduções aqui apresentadas foram preparadas pela autora da resenha.

7 Cf. BOUSSOFARA-OMAR, 2006.
} 
O artigo de Anne-Marie Simon-Vanedbergen et a ${ }^{8}$ compreende uma análise das pressuposições nas declarações de políticos ingleses, holandeses e suecos. Esse estudo visa à exposição das ideologias subjacentes às declarações dos políticos que auxiliam na manipulação do público. O poder das pressuposições enquanto recurso linguístico jaz no seu caráter persuasivo, criando a impressão de que se pode tomar a informação pressuposta como garantida. Esse recurso é poderoso no discurso político também porque, à medida em que se tentam estabelecer posições em comum e solidariedade, dificulta-se a contestação das ideias. De acordo com os autores, uma pressuposição "tem um enorme potencial manipulador", lançando-se ao público uma informação que se pode reconhecer falsa, mas que talvez não possa ser discutida e provada como tal. Um dos contextos em que esta possibilidade pode ser verificada é no âmbito da discussão política mediada pela televisão.

Na quarta seção, "Language and the media", três artigos discutem a relação entre linguagem e representação através dos meios de comunicação. O primeiro artigo, "Rache and ethnicity in the media", de Anthea Irwin, ${ }^{9}$ apresenta uma consideração crítica da cobertura em um jornal escocês de um caso de rapto/saída voluntária de uma jovem de origem paquistanesa da Escócia para o Paquistão. A autora apresenta uma consideração detalhada das identidades atribuídas aos protagonistas do episódio e de como estas se modificam a cada dia, à medida que os eventos se desenvolvem. Sobressai-se, nos textos jornalísticos analisados, uma visão preconceituosa do "outro", no caso, a família de origem paquistanesa, expressa sobretudo através de contrastes implícitos, que opõem o elemento nacional ao estrangeiro. Esse artigo traz uma importante contribuição ao conjunto de textos neste livro por apresentar análise de textos escritos, jornalísticos, tendo em vista a tendência de focalizar a fala e o estudo de manifestações linguísticas orais.

O artigo seguinte, "Those naughty teenage girls: Japanese Kogals, slang, and media assessment", de Laura Miller, ${ }^{10}$ expõe a análise de como a mídia japonesa apresenta ao público opiniões sobre o estilo deste grupo, as kogals. A primeira parte do artigo apresenta as tipologias do modelo feminino na sociedade japonesa, discutindo como as kogals contradizem os modelos normalmente aceitos por ferirem o padrão de feminilidade aceitável. As chamadas kogals aderem a uma estética particular, que inclui um modo de vestir-se e de expressar-se que quebra as regras e redefine "female-centered coolness" (MOONEY et al., 2011, p.121). O grupo também se apropria de uma forma particular de expressar-se linguisticamente, o que inclui a modificação do signo escrito, principalmente

\footnotetext{
8 Cf. SIMON-VANDBERGEN; WHITE; AIJMER, 1999.

9 Cf. IRWIN, 2008.

10 Cf. MILLER, 2011.
} 
através de mensagens de texto e do uso de formas tipicamente presentes no discurso masculino, tal como os honoríficos. As referências às kogals na mídia japonesa fazem-nas parecer "insípidas" e "insensatas". Entretanto, de acordo com Miller, tais retratações não são o verdadeiro foco da mídia, mas refletem tendências mais arraigadas na sociedade japonesa, que limitam a autonomia feminina e promovem a manutenção de modelos de consumo e de comportamento mais tradicionais.

O terceiro artigo da seção intitula-se "Authenticating talk: building public identities in audience participation broadcasting" e é da autoria de Joanna Thornborrow. ${ }^{11}$ Trata-se de uma consideração sobre como os ouvintes-participantes de programas de rádio que telefonam para expressar suas opiniões constroem suas identidades de forma a legitimar sua contribuição para a transmissão. A autora considera participações de ouvintes a um programa de notícias que conta também com a colaboração da figura de um especialista. Como modelo de participação deste tipo de interação, a transmissão radiofônica em questão conta com o papel de um locutor, que atribui o direito ao turno a cada participante e, assim, organiza a interação. Tais programas estruturam-se na expressão de pontos de vista sobre um determinado tópico e, de certa forma, permitem o estabelecimento do âmbito participativo de cada colaborador, sobressaindo-se os papéis de especialista e colaborador leigo - o ouvinte. Mesmo assim, de acordo com a discussão de Thornborrow, os colaboradores-ouvintes-leigos fazem mais do que dar uma opinião: por suprirem informações sobre si mesmos e salientarem aspectos de sua identidade, eles garantem a relevância da sua participação pública naquele momento (MOONEY et al., 2011, p.133). Esse artigo faz uma aplicação dos princípios da análise da conversa, especificamente no que tange à atribuição de direito ao turno e às categorias relevantes para se fazê-lo.

Na quinta seção, "Language and gender", três artigos discutem como a linguagem pode ser analisada com vistas a compreender relações de identidade e gênero. O primeiro artigo, "Linguistic sexism and feminist linguistic activism", de Anne Pauwels, ${ }^{12}$ considera os passos que têm sido dados para eliminar uma linguagem sexista e promover maior inclusão feminina, ou mesmo o amplo uso de uma linguagem mais neutra. A autora comenta a trajetória de algumas destas modificações à luz das propostas feministas e como consequências destas. A sequência que tem início com o planejamento das mudanças, sua implementação e efetiva adoção é discutida, à medida que Pauwels trata especificamente sobre os tipos de mudanças que podem ser esperadas, os potenciais benefícios resultantes e passos que podem ser dados em direção a uma linguagem mais igualitária. A autora conclui com uma perspectiva otimista sobre a medidas tomadas, afirmando

11 Cf. THORNBORROW, 2001

12 Cf. PAWLES, 2003. 
que iniciativas no sentido de expor a ideologia linguística nas comunidades de fala podem contribuir para "desafiar a hegemonia de sentidos promovidas por grupos e culturas dominantes", tais como a masculina ${ }^{13}$ (MOONEY et al., 2011, p.160).

$\mathrm{O}$ artigo de Mary Talbot, ${ }^{14}$ “'I wish you'd stop interrupting me': interruptions and asymetries in speaker-rights in equal encounters", considera a relação entre dominância masculina e interrupções. Como ponto de partida, o artigo apresenta a definição do que se pode considerar interrupção e fala simultânea. A autora critica o estudo de West e Zimmerman sobre a preponderância de interrupções de falantes masculinos ao turno de interlocutores femininos. Além disso, Talbot aponta as falhas do primeiro estudo, destacando que uma alternativa adequada para o estudo deste fenômeno seria considerar as relações de poder travadas no âmbito das interações linguísticas. Desta forma, seria a posição relativa de cada participante, no âmbito da interação, e não o seu sexo, o que exerceria um efeito significativo sobre o número e tipos de interrupções (MOONEY et al., 2011, p.167).

O segundo artigo de Deborah Cameron na coletânea, "Performing gender identity: young men's talk and the construction of heterosexual masculinity", apresenta uma leitura alternativa de uma conversa anteriormente analisada por um dos alunos da autora. Na primeira versão, o aluno de Cameron apresenta a conversa como protótipo dos tópicos sobre os quais homens jovens falam entre si, incluindo esportes, mulheres e bebidas. Entretanto a minuciosa análise apresentada por Cameron contém uma versão completamente distinta da que o seu aluno realizou, contrastando com esta por revelar que homens jovens também falam sobre tópicos que não são tipicamente associados com seu grupo. A análise de Cameron é relevante por ressaltar que a compreensão de fenômenos linguísticos no âmbito interacional precisa ser alcançada através do estudo do contexto imediato. Além disso, como a autora mostra, apesar de a Sociolinguística defender a noção de que indivíduos são definidos pela forma como falam, uma abordagem pós-modernista considera que esta definição se estrutura, precisamente, em função do conteúdo, mas também dos recursos linguísticos empregados para transmiti-lo (MOONEY et al., 2011, p.180). Esta abordagem para os estudos da linguagem permite observar que os atores sociais também agem de modo a "engajar-se em atos de transgressão, subversão, e resistência"15 (MOONEY et al., 2011, p.181). No caso dos dados analisados, Cameron revela que os homens conversam informalmente, construindo cooperação, simultaneamente à ação de falar sobre outros - o que corresponde à definição de "fofoca", "gênero" frequentemente atribuído a falantes

13 No original, "[T]hese linguistic initiative and actions, many of which have been undertaken at the grassroots level, have made a major contribution to exposing ideologization of linguistic meanings to the speech community at large and to challenging the hegemony of the meanings promoted and authorized by the dominant group or culture, in this case, men."

14 Cf. TALBOT, 1992.

15 No original, "engage in acts of transgression, subversion and resistance" 
femininos. O artigo de Cameron contribui com a perspectiva de que, estudos sobre as relações entre linguagem e gênero podem ser mais adequadamente conduzidos se são evitadas categorias, ou noções, estabelecidas a priori, tais como as de que há tópicos sobre os quais indivíduos do gênero masculino ou feminino tratam, ou gêneros textuais que são mais comumente produzidos por um ou outro grupo.

Na sexta seção, "Language and ethnicity", dois artigos discutem as relações de poder construídas no âmbito do uso linguístico em seus limites com relações étnicas. O primeiro artigo, Racist discourse, de Teun van Dijk, ${ }^{16}$ faz uma adequada introdução ao estudo do discurso racista, apresentando dos tipos: 1) aquele dirigido a um grupo etnicamente diferente e 2) aquele sobre um grupo etnicamente diferente. O primeiro tipo é discriminatório nos modos em que o grupo dominante interage com o grupo minoritário, ao passo que, o segundo tipo de discurso racista pode ser mais sutil na construção de linguagem que se refira ao grupo minoritário. Considerando que, atualmente, em muitas culturas o discurso discriminatório é politicamente incorreto, as formas linguísticas discriminatórias podem assumir feições mais sutis e indiretas. Para o autor, as estratégias de tal discurso podem ser variadas, figurando em vários níveis da atividade linguística, sejam estes o universo sintático, semântico, pragmático, o estilo, as figuras de retórica, ou ainda os elementos visuais e os sons ((MOONEY et al., 2011, p.200). A característica mais importante do discurso racista é, porém, a construção da oposição nós X eles, os outros. O autor faz também sugestões importantes de leitura para se desenvolver estudos desta natureza, com textos que compreendem a análise do discurso racista em países europeus e no Canadá.

O próximo artigo da coletânea é "Legal recognition of cultural differences in communication: the case of Robin Kina", de Diana Eades, ${ }^{17}$ compreendendo uma detalhada consideração de um caso judicial no qual o conhecimento de uma comunidade linguística foi fundamental em informar a decisão legal envolvendo uma prisioneira australiana aborígene. $\mathrm{O}$ artigo de Eades recapitula a trajetória de Robyn Kina, uma mulher presa por ter assassinado o companheiro em legítima defesa, e de como o tipo de conselho legal que ela recebeu afetou negativamente seu julgamento. Eades, especialista em Inglês Aborígene - um dialeto que difere sistematicamente do Inglês Australiano Padrão (MOONEY et al., 2011, p.205) -, é chamada para oferecer seu parecer à corte sobre os modos específicos de comunicação que marcam as diferenças entres estes dois modelos linguísticos. De acordo com Eades, falantes da comunidade linguística em questão possuem modos particulares de se expressar, caracterizados por significativas diferenças gramaticais e pragmáticas. O desconhecimento dessas peculiaridades nas circunstâncias de interação entre falantes de inglês aborígene e falantes de inglês

16 Cf. VAN DICK, 2004.

17 Cf. EADES, 2008. 
australiano padrão pode gerar mal entendidos, cujas consequências podem afetar negativa e injustamente os membros do grupo minoritário. Eades discute as formas como uma situação de interação entre advogado e aborígene poderiam ser desfavoráveis para a coleta de informações que poderiam potencialmente auxiliar na construção da defesa. Por exemplo, como Eades mostra, o modo de procurar informações na comunidade aborígene envolve períodos longos de silêncio e a ausência de perguntas diretas que possam ser interpretadas como uma violação à privacidade dos indivíduos (MOONEY et al., 2011, p.208). Eades, então, contrasta o depoimento de Robyn Kina aos seus advogados e a um canal de televisão. No primeiro caso, as interações foram realizadas observando-se um modelo mais formal, típico do encontro advogado-réu, diferindo das entrevistas cedidas a um canal de televisão e para as quais os produtores e jornalistas envolvidos prepararam-se, primeiro, visitando Kina e tentando fazê-la sentir-se confortável, antes de iniciar a coleta de informações e a gravação da entrevista. Os dois modelos de entrevista renderam resultados significativamente diferentes, na medida em que, nas interações com os advogados, Kina mostrou-se reticente, mas mais à vontade, ao ponto de voluntariar várias narrativas, no segundo caso, as interações com os jornalistas. Esse estudo apresenta os resultados da aplicação prática dos princípios da Sociolinguística, mostrando de que formas o (des) conhecimento dos modos de comunicar de uma comunidade linguística pode ter consequências cujas repercussões podem afetar decisões de largo alcance, tais como as judiciais.

Na sétima seção, "Language and age", encontram-se dois artigos que relacionam linguagem e grupo etário: o primeiro, a linguagem de idosos e, o segundo, de adolescentes. O artigo de Sinfree Makoni e Karen Grainger, ${ }^{18}$ "Comparative gerontolinguistics: characterizing discourses in caring institutions in South Africa and the United Kingdon", apresenta os resultados de uma análise qualitativa da interação entre pacientes de instituições de cuidado a idosos e seus funcionários. Makoni e Grainger discutem como os empregados usam discurso controlador no exercício das atividades cotidianas em asilos, no lidar com os idosos. As formas que esta linguagem assume incluem expressões de carinho, discurso infatilizante e discurso lúdico. Entretanto, como os autores argumentam, estas formas discursivas visam a manter a posição dos funcionários, enquanto estes desempenham atividades e solicitam a cooperação dos idosos. Trata-se de uma estratégia para alcançar o equilíbrio entre os requerimentos de eficiência e de demonstrar preocupação com os pacientes (MOONEY et al., 2011, p.235). A comparação entre culturas, i.e., Reino Unido e África do Sul, permite concluir que a linguagem empregada pelos funcionários dos asilos é orientada para o cumprimento de tarefas, comprometendo a integridade pessoal dos residentes, e

18 Cf. MAKONI; GRAINGER, 2002. 
que, por esta razão, a maior parte da expressão verbal nas interações analisadas visa ao objetivo de concluir um serviço.

O artigo de Penelope Eckert, ${ }^{19}$ "Adolescent language", inicia com uma consideração das dinâmicas envolvidas nas atitudes linguísticas. A autora justifica sua análise da linguagem adolescente com uma pertinente observação de que se costuma apontar em outros a presença ou ausência de determinadas marcas que caracterizam um sotaque, esquecendo-se de que todos os falantes possuem um. Esta tendência de atribuir valores à fala de determinados grupos é parte do que constitui poder na sociedade - a habilidade de definir o que é "normal" (MOONEY et al., 2011, p.238). Eckert define alguns níveis linguísticos sobre os quais se detém, à medida que explica a razão para marcarem-se as diferenças em um determinado grupo de falantes. Como exemplo, a autora analisa características fonético-fonológicas na expressão de grupos de jovens em uma escola de nível médio, no norte da Califórnia. Os resultados do estudo de Eckert demonstram de que formas jocks - classe média, voltados para a cultura acadêmica - e burnouts - voltados para o ingresso no mercado de trabalho - usam traços linguísticos que contribuem para construir suas identidades, de modo a refletir sua "orientação para a instituição globalizante da escola e para a área urbana local"20 (MOONEY et al., 2011, p.243). Alguns dos traços analisados pela autora foram a dupla negação, o alteamento do núcleo vocálico no grupo /ay/, e o fechamento da vogal média baixa $/ \varepsilon /$.

Na oitava seção, "Language and social class", há três artigos que discutem as relações entre o desempenho linguístico e classe social. O primeiro, "Mobility, meritocracy and dialect levelling: the fading (and phasing) out of received pronunciation", é de autoria de Paul Kerswill, ${ }^{21}$ que discute o apagamento das diferenças dialetais no inglês britânico, cujas causas são: 1) econômicas - perda de economias e comunidades agrícolas, conduzindo um maior contingente populacional a migrar em direção aos centros urbanos; 2) maior contato interdialetal - contato mais intenso entre indivíduos falantes de dialetos diferentes; 3) as consequentes modificações nas redes de contatos sociais proporcionada pela distância da família imediata. De acordo com Kerswill, este contexto tem proporcionado a nivelação dialetal com padronização (MOONEY et al., 2011, p.258). A variante resultante das modificações é um dialeto de características intermediárias entre a variante de prestígio e a não padrão, ou "Estuary English" (MOONEY et al., 2011, p.259). O surgimento dessa variedade e sua divulgação através dos meios de comunicação tem trazido à tona conflitantes opiniões e

19 Cf. ECKERT, 2004.

20 No original: "The linguistic style of the jocks and burnouts reflect their orientation to the globalizing institution of the school, on the one hand, and to the local urban area on the other".

21 Cf. KERSWILL, 2001. 
atitudes que perpassam vários estágios da sociedade inglesa. O autor também comenta a natureza e as vantagens das mudanças dialetais, particularmente as que estão relacionadas a noções de classe social.

O segundo artigo da seção, de William Labov, ${ }^{22}$ constitui material essencial para estudantes interessados no desenvolvimento da Sociolinguística moderna como subdisciplina da Linguística e, em particular, nos estudos do autor sobre variação. "Academic ignorance and black intelligence" foi um artigo originalmente publicado na revista Atlantic, no número de dezembro de 1971, no qual Labov discutia a controvérsia sobre a razão pela qual crianças de escolas urbanas mostram um baixo desempenho escolar. ${ }^{23}$ (MOONEY et al., 2011, p.266). O hoje clássico artigo de Labov aponta razões intrínsecas ao modo de comunicar de indivíduos provenientes de diferentes classes sociais e a falta de conhecimento destes modos particulares de usar a linguagem como responsáveis por criar a errônea interpretação para o insucesso de crianças negras nas escolas americanas. Ao exemplificar com excertos de interações em situações de entrevistas sociolinguísticas nas quais os falantes compartilhavam do conhecimento dialetal dos informantes, Labov deixa claro que a interpretação da suposta deficiência cognitiva nas escolas americanas, há quatro décadas, baseava-se em uma premissa equivocada, que enxergava a inabilidade de produzir estilos e tipos textuais como reflexo de deficiências de ordem que escapavam ao âmbito social. O argumento de Labov e a sua demonstração detalhada da habilidade de crianças negras, habitantes de "guetos", de produzir linguagem rica em expressões e imagens iluminou o caminho para outras abordagens que explicassem as diferenças e a interação entre aqueles que não partilhavam do conhecimento para reconhecêlas. O artigo de Labov tem quarenta anos, mas a discussão nele ensejada é ainda corrente e relevante para se explicarem e entenderem as naturezas das diferenças na produção e recepção de falares e escreveres distintos.

O próximo artigo, de Michael Gos, ${ }^{24}$ "Overcoming social class markers: preparing working class students for college", oferece uma terceira perspectiva sobre as relações de poder na linguagem vistas como consequência ou no âmbito de classes sociais. O argumento de Gos é que estudantes universitários provenientes das classes trabalhadoras, menos privilegiadas, deparam-se com uma tarefa desafiadora ao ingressarem no sistema educacional universitário. Para o autor, parte desse desafio reside na incongruência entre o tipo de produção linguística, oral e escrita, que se espera desses estudantes e o tipo de material linguístico que tais estudantes produzem no seu dia a dia, como parte de sua

\footnotetext{
22 Cf. LABOV, 1971.

23 No original: "the controversy over why children in the inner-city schools show such low educational achievement".

24 Cf. GOS, 1995.
} 
realidade. De acordo com o autor, preparar estudantes do ensino médio para esse novo estágio educacional requer um trabalho que antecipe as dificuldades e combata a formação de hábitos contraproducentes. Dessa forma, Gos aponta dois pontos importantes: 1) de acordo com o autor, estudantes provenientes da classe média, no caso dos Estados Unidos, por exemplo, estão mais acostumados a pensar criticamente, pois a estrutura familiar a que têm acesso assim o favorece; por outro lado, estudantes de classes sociais desprivilegiadas estão mais acostumados a memorizar material, o que representa grande dificuldade ao tentarem avançar a um outro modelo para reter informações de maneira crítica; 2) o autor também discute como indivíduos geralmente são julgados com base na forma como falam e como isso também se aplica no caso de estudantes universitários provenientes de classes trabalhadoras. O autor então aponta para a necessidade de que o trabalho de preparação para a universidade também inclua uma formação linguística aplicada aos novos contextos de fala no ambiente acadêmico, universitário. Tal preparação deve começar desde o ensino médio de modo a se proporcionar uma transição menos "traumática" (MOONEY et al., 2011, p.287).

Na nona seção, "Language and identity", há três artigos que discutem as relações entre língua, poder e identidade. O primeiro, "The meaning of style", de Penelope Eckert, ${ }^{25}$ é uma consideração das formas como a linguagem pode ser usada de modo a permitir criar-se uma noção da identidade dos falantes. A autora inicia com uma breve discussão do trabalho de Labov em Martha's Vineyard, mostrando como já, naquele trabalho, o autor revelara métodos para chegar a conhecer-se mais sobre um individuo, suas intenções e características sociais por meio da forma como se fala. A variação fonológica, tal como discutida por Labov e empregada posteriormente por Eckert no seu estudo sobre comunidades de falantes jovens - jocks and burnouts -, é um dos indicadores característicos de falantes de uma determinada comunidade de práticas. A propriedade linguística de poder associar significados não só ao que se diz, mas também à forma específica empregada pelos falantes de uma dada língua para fazê-lo aponta para seu valor indexicalizador. Como Eckert discute, a linguagem faz parte de um sistema semiótico que inclui o modo de vestir-se, a preferência musical, as atividades e posições assumidas (MOONEY et al., 2011, p.301). A noção de estilo, então, é apropriada ao se tentar compreender como falantes de qualquer língua podem, dadas as circunstâncias, empregar modos de falar característicos, sejam estes marcados por traços fonológicos ou lexicais, com o objetivo de projetar ideias de si, ou mesmo posições ideológicas.

No segundo artigo da seção, "The man with the baseball bat", John Olsson²6 discute traços característicos de um dialeto inglês, mostrando como esses foram

25 Cf. ECKERT, 2003.

26 Cf. OLSSON, 2009 
úteis em um caso policial referente a uma ameaça feita por telefone. O artigo é mais um exemplo no volume de como a linguística pode ser posta em serviço de outras áreas do conhecimento humano, com um fim de caráter mais prático - descobrir a proveniência de uma ameaça e apontar os responsáveis. O artigo descreve brevemente os resultados do estudo de Olsson e como sua análise serviu para incriminar, no caso, justamente, o suspeito.

O terceiro artigo do volume é a contribuição de uma pesquisadora brasileira, Audrei Gesser, ${ }^{27}$ intitulado "Hearing people in the land of the deaf: an ethnographic account". Gesser registra sua pesquisa etnográfica em Gallaudet University, Washignton, DC - uma instituição de ensino superior para estudantes que possuem deficiência auditiva. As observações de Gesser destacam a importância de usar a linguagem de sinais no contexto de interações na universidade, ao passo que a atitude geral para com os que não a empregam é de que ouvir é percebido "como se fosse uma grave falha"28 ( MOONEY et al., 2011, p.317).

Na décima seção, "Standard Englishes", há três artigos em que se aborda o uso do idioma inglês em três contextos distintos. No primeiro, "Asias's Englishes and world Englishes: interview with Braj B. Kachru", Jacqueline Lam Kam-Mei ${ }^{29}$ apresenta as principais ideias de uma entrevista com o professor creditado com o primeiro uso do termo "World English". Um dos pontos de interesse na entrevista é a discussão de como o idioma inglês tem se multiplicado em um universo de contatos que a rede socioeconômica cria. Além disso, como o autor mostra, a expansão do uso deste idioma tem gerado, na Ásia, por exemplo, maior produção linguística em uma variedade de gêneros discursivos, trazendo à tona a necessidade de outras explicações para fenômenos relativos à língua na região. Por exemplo, Kachru afirma: "English is an Asian language if we make a distinction between GENETIC NATIVENESS of a language and its FUNCTIONAL NATIVENESS." (MOONEY et al., 2011, p.334, grifo do autor). Trata-se de uma reflexão sobre o papel que uma língua tão difundida como o inglês pode vir a ter em comunidades tão distantes, cultural e geograficamente, dos países com os quais se está acostumado a associá-la. Dadas as variedades no uso de línguas, motivadas pela necessidade de contato profissional, reflexões como a de Kachru podem render sugestões relevantes para a abordagem do estudo de contato linguístico e das resultantes variedades.

No segundo artigo da seção, "English as official state language in Ohio: economy trumps ideology", Betsy Evans ${ }^{30}$ apresenta uma discussão sobre o

\footnotetext{
27 Cf. GESSER, 2007.

28 No original: "as if it were a sin".

29 Cf. LAM KAM-MEI, 2008.

30 Cf. EVANS, 2010.
} 
debate político travado no estado americano de Ohio face à apresentação de uma lei (HB 553) que requeria a aceitação do inglês como língua oficial do estado. Apesar dos argumentos em favor de defender-se a unidade estatal e nacional ao se proporem tais leis, no caso de Ohio, na mesma época em que os políticos estaduais a apresentaram, especulava-se que uma montadora japonesa instalarse-ia no estado. A autora conclui que o resultado negativo da proposta de lei evidencia e apoia a noção de que as "forças de mercado" podem ter influência nas políticas linguísticas (MOONEY et al., 2011, p.343).

O último artigo da seção e do livro, "English as a lingua franca: interpretations and attitudes", de Jennifer Jenkins, ${ }^{31}$ discute como falantes de inglês provenientes de diversas culturas linguísticas empregam esse idioma para comunicar-se. Essa discussão apresenta alguns pontos sobre as negociações travadas pelos falantes de inglês como língua franca, incluindo a aceitação de formas não conformes à língua padrão, considerando a maior ênfase neste tipo de contatos na comunicação e não na precisão. Os pontos de interesse neste artigo convergem para a conclusão de que, dados os contatos travados por indivíduos falantes de inglês de diferentes regiões, a tendência é desenvolverem-se formas que, em processo de evolução, apresentem características distantes da variedade padrão, isto é, "erros sistemáticos", mas que são aceitáveis por serem eficazes em viabilizar a comunicação. Os intensos entrelaces proporcionados por um mundo cada vez mais "conectado" tornam esse tipo de estudo bastante relevante, pois, no futuro, potencialmente, serão outras as línguas de contato entre diferentes povos.

A seleção das seções do livro é pertinente e os artigos bons exemplos da aplicação da ciência linguística. Um dos aspectos em que o livro talvez pudesse ter feito uma melhor contribuição é na organização das seções. Tendo em vista que o público alvo são estudantes iniciantes da Línguística, talvez a progressão dos artigos pudesse seguir uma ordem mais lógica do ponto de vista do desenvolvimento da própria disciplina e das suas abordagens. Assim, artigos seminais, tais como os de Labov (Linguagem e classe social) eWhorf (Linguagem e pensamento) talvez pudessem anteceder os artigos mais recentes. Apesar de o livro fazer uma boa contribuição por acrescentar sugestões de leituras adicionais e de filmes, é possível que mais pudesse ter sido dito sobre a relevância de se incluírem não apenas artigos de linguistas reconhecidos internacionalmente, mas também de novos profissionais da disciplina. Além disso, existem trabalhos importantes, cujas abordagens exemplificam a intersecção entre linguagem, poder e sociedade, que não foram incluídos na coletânea. Um exemplo dessa ausência são os trabalhos do grupo de sociolinguistas interacionais, tais como Tannen $(1986,1996)$ e Schiffrin $(1996,2000)$. Trata-se de artigos relevantes para qualquer consideração que combine a inclusão de traços externos à linguagem

31 Cf. JENKINS, 2009. 
e seu impacto para uma interação, e que representam bem esta subdisciplina linguística. Dado que é tão grande a variedade de abordagens ao estudo da linguagem, apresentar a justificativa para a inclusão dos artigos e a ausência de reconhecidos teóricos linguistas contemporâneos seria uma adequada adição ao importante volume.

\section{REFERÊNCIAS}

BOUSSOFARA-OMAR, N. Learning the 'linguistic habitus' of a politician: a presidential authoritative voice in the making'. Journal of Language and Politics, United Kingdom, v.5, n.3, p.325-328, 2006.

CAMERON, D. Verbal hygiene. Routledge: London, 1995.

EADES, D. Telling and retelling your story in court: questions, assumptions and intercultural implications. Current Issues in Criminal Justice, Australian,v.20, n.2, p.209-230, 2008.

ECKERT, P. Adolescent language. In: FINEGAN, E.; RICKFORD, J. R. (Ed.). Language in the USA: themes for the twenty-first century. Cambridge: Cambridge University Press, 2004. p.361-374.

The meaning of style. In: ANNUAL SYMPOSIUM ABOUT LANGUAGE AND SOCIETY, 11., 2003, Austin. Proceedings... Austin: Texas Linguistic Forum, 2003. p.41-53.

EVANS, B. English as official state language in Ohio: market forces trump ideology. In: KELLY-HOLMES, H.; MAUTNER, G. (Ed.). Language and the market. London: Palgrave Macmillan, 2010. p.161-170.

FAIRCLOUGH, N. Global capitalism and critical awareness of language. Language Awareness, Clevedon, v.8, n.2, p.71-83, 1999.

GESSER, A. Learning about hearing people in the land of the deaf: an ethnographic account. Sign Language Studies, Washington, v.7, n.3, p.269-283, 2007.

GOS, M. Overcoming social class markers: preparing working class students for college. The Clearing House, [S.1.], v.69, n.1, p.30-34, 1995.

IRWIN, A. The media in Scotland. Edinburgh: Edinburgh University Press, 2008.

KERSWILL, P. (2001a). Mobility, meritocracy and dialect levelling: the fading (and phasing) out of Received Pronunciation. In: RAJAMÄE, P.; VOGELBERG, K. (Ed.). British studies in the new millennium: the challenge of the grassroots. Tartu: University of Tartu, 2001. p.45-58. 
LABOV, W. Academic ignorance and black intelligence. The Atlantic, Boston, v.229, n.6, p.59-67, 1972.

LAM KAM-MEI, J. Asia's Englishes and world Englishes: interview with Braj B. Kachru. English Today, Rondebosch, v.16, n.1, p.17-22, 2008.

MAKONI, S.; GRAINGER, K. Comparative gerontolinguistics: characterizing discourses in caring institutions in South Africa and the United Kingdom. Journal of Social Issues, Malden, v.58, n.4, p.805-824, 2002.

MILLER, L. Those naughty teenage girls: Japanese kogals, slang, and media assessments. Journal of Linguistic Anthropology, Long Beach, v.14, n.2, p.225247, 2004.

NUNGERG, G. Media, label whores. American Prospect, Washington, v.13, n.8, 2002.

OLSSON, J. The man with the baseball bat. Wordcrime: solving crime through forensic linguistics. London: Continuum International Publishers, 2009.

PAUWELS, A. Linguistic sexism and feminist linguistic activism. In: HOLMES, J.; MEYERHOFF, M. (Ed.). The handbook of language and gender. Oxford: Basil Blackwell, 2003. p.550-570.

PULLUM, A. The great Eskimo vocabular hoax and other irreverente essays in the study of language. Chicago: University of Chicago Press, 1991.

SCHIFFRIN, D. Mother/daughter discourse in a Holocaust oral History: "because then you admit that you're guilty". Narrative Inquiry, Amsterdam, v.10, n.1, p.144, 2000.

Narrative as self-portrait: sociolinguistic. Constructions of identity. Language in Society, Cambridge, v.25, n.2, p.167-201, 1996.

SIMON-VANDENBERGEN, A. M.; WHITE, P. R. R.; AIJMER, K. Presuposition and 'taking for granted' in mass communicated political argument: an illustration from British, Flemish and Swedish political colloquy. In: FLETZER, A.; LAUERBACH, G. (Ed.). Political discourse in the midia: cross-cultural perspectives. Amsterdan: John Benjamins, 1999. p.31-74. (Pragmatics and Beyond New Series).

TALBOT, M. "I wish you'd stop interrupting me!” Interruptions and asymmetries in speaker-rights in "equal-encounters". Journal of Pragmatics, Amsterdam, v.18, n.5, p.451-466, 1992.

TANNEN, D. The relativity of linguistic strategies: rethinking power and solidarity in gender and dominance." In: Gender and discourse. New York: Oxford University Press, 1996. p.19-52. 
That's not what I mean: how meaning in conversation styles makes or breaks relationships. New York: Ballantine, 1986.

THORNBORROW, J. Authenticating talk: building public identities in audience participation broadcasting. Discourse Studies, [S.1.], v.3, n.4, p.459-479, 2001.

VAN-DIKJ,T. Racist discourse. In: CASHMERE, E. (Ed.). Routledge Encyclopaedia of race and ethnic studies. London: Routledge, 2004. p.351-355.

WHORF, B. L. The relation of habitual thought and behavior to language. In: CARROLL, J. B. (Ed.). Language, thought and reality. Selected writings of Benjamin Lee Whorf. Cambridge: MIT, 1956. p.134-159.

Recebido em julho de 2011.

Aprovado em novembro de 2011. 